\title{
OP32
}

\section{ENERGY SAVING POTENTIAL FOR INTEGRATED DAYLIGHTING AND ELECTRIC LIGHTING DESIGN VIA USER-DRIVEN SOLUTIONS: A LITERATURE REVIEW \\ Niko Gentile et al.}

DOI 10.25039/x46.2019.OP32

from

CIE x046:2019

Proceedings

of the

29th CIE SESSION

Washington D.C., USA, June 14 - 22, 2019

(DOI 10.25039/x46.2019)

The paper has been presented at the 29th CIE Session, Washington D.C., USA, June 14-22, 2019. It has not been peer-reviewed by CIE.

(C) CIE 2019

All rights reserved. Unless otherwise specified, no part of this publication may be reproduced or utilized in any form or by any means, electronic or mechanical, including photocopying and microfilm, without permission in writing from CIE Central Bureau at the address below. Any mention of organizations or products does not imply endorsement by the CIE.

This paper is made available open access for individual use. However, in all other cases all rights are reserved unless explicit permission is sought from and given by the CIE.

CIE Central Bureau

Babenbergerstrasse 9

A-1010 Vienna

Austria

Tel.: +43 17143187

e-mail: ciecb@cie.co.at

www.cie.co.at 


\title{
ENERGY SAVING POTENTIAL FOR INTEGRATED DAYLIGHTING AND ELECTRIC LIGHTING DESIGN VIA USER-DRIVEN SOLUTIONS: A LITERATURE REVIEW
}

\author{
Gentile, N. ${ }^{1}$, Osterhaus, W. ${ }^{2}$, Altomonte, S. ${ }^{3}$, García Alvarez, M. ${ }^{2}$, Garcia-Hansen, V. ${ }^{4}$, Naves \\ David Amorim, C. ${ }^{5}$, Obradovic, B. ${ }^{6}$ \\ ${ }^{1}$ Lund University, Lund, SWEDEN, ${ }^{2}$ Aarhus University, Aarhus, DENMARK, ${ }^{3}$ Université \\ Catholique de Louvain, Louvain-la-Neuve, BELGIUM, ${ }^{4}$ Queensland University of Technology, \\ Brisbane, AUSTRALIA, ${ }^{5}$ University of Brasília, Brasília, BRAZIL, ${ }^{6}$ Norconsult AS, Oslo, \\ NORWAY \\ Niko.Gentile@ebd.Ith.se
}

DOI $10.25039 / \times 46.2019 .0 P 32$

\begin{abstract}
Measures for the reduction of electric energy loads for lighting have predominantly focussed on increasing the efficiency of lighting systems. This efficiency has now reached levels unthinkable a few decades ago. However, a focus on mere efficiency is physically limiting, and does not necessarily ensure that the anticipated energy savings actually materialise. This paper presents a literature survey aimed at identifying control strategies and user behaviours leading to a reduction in lighting energy use. Whenever possible, the strategies and behaviours discussed are supported by quantitative data. This survey is part of a more extensive review of the potential for reducing energy use through the integrated design of daylight and electric lighting and their control systems. It concludes with identifying key aspects for lighting control decisions with respect to daylight use, control strategies, control interfaces, feedback systems, rebound effects and social norms regarding user behaviour and makes recommendations for further research.
\end{abstract}

Keywords: Integrated Lighting Design, Daylighting, Electric Lighting, Energy Use, UserCentered Controls, Control Interfaces, Social Norms, Behaviour.

\section{The role of the building user in saving energy}

A few years ago an article with the title "Buildings don't use energy, people do" appeared in the literature (Janda, 2011). It recognised that building energy needs are predominantly triggered by the presence and activities of occupants and their comfort requirements. Recent years have also seen increasing research focusing on the characterization of human behaviour and related energy-use patterns in buildings. One example is the extensive work carried out by Annex 66 of the International Energy Agency (IEA) Energy in Buildings and Communities (EBC) programme (IEA-EBC, 2018) "Definition and Simulation of Occupant Behavior in Buildings".

Focusing on lighting, in a technological perspective, electricity demands can be lowered by at least $50 \%$ by using existing efficient technologies (Dubois et al., 2015), while daylighting integration schemes could provide further savings ( $\mathrm{hm}$ et al., 2009). The use of efficient technologies can certainly foster energy savings, but this is a more complex domain that also needs to consider individual energy-related behaviours of building occupants, as well as the role of building owners and/or managers (Oikonomou et al., 2009).

In this paper, we define "user-driven strategies" as those methods that depend on the user, rather than on the system, to achieve energy savings. The "active" and "passive" user - who, respectively, does and does not operate (day)lighting control systems (Reinhart, 2004), will serve as an example. In the presence of many passive users, a technical solution for energyefficiency would be to install an occupancy on/off sensor for controlling the electric lighting. In contrast, a user-driven strategy for energy savings would be to transform passive users into active users by informing them about the environmental impact of their behaviour with respect to the use of lighting control systems. On this premise, this paper aims to illustrate user-driven strategies for energy savings in integrated lighting design. When possible, the study also 
attempts to qualify and quantify potential energy savings linked to each strategy. To fulfil these objectives, the paper presents an exploratory review of the literature. Rather than providing a comprehensive overview of the topic, the idea is to raise awareness on various user- and energy-related aspects that are often overlooked within the integrated building design process.

This work is part of a wider literature review focusing on the energy savings potential of usercentred integrated lighting solutions. The work is undertaken in the context of the IEA joint Solar Heating Cooling (SHC) and Energy in Buildings and Communities (EBC) programs Task 61/Annex 77 "Integrated Solutions for Daylighting and Electric Lighting: From component to user-centred system efficiency", running from 2018 to 2021. The overall objective of the work is to foster the integration of daylighting and electric lighting solutions towards higher user satisfaction and energy savings (de Boer, 2018).

\section{Method}

In this literature survey, peer-reviewed studies, mainly published in the last decade, were collected and critically evaluated. The search keywords were gathered from an appraisal based on the contributions of 30 lighting experts with different competences and areas of expertise. The keywords were entered into relevant databases - e.g., Scopus, Web of Science, IEEE Xplore - in order to retrieve a first set of fundamental papers. Other papers were gathered via cross-referencing from the first set of publications. The papers were grouped by topic according to the strategies they described. Based on the findings, a reasoned estimate of potential energy savings was established for each group of topics/strategies. Topics and strategies included both electric lighting and daylighting, with emphasis on integrated systems and solutions.

\section{Results}

The literature survey highlighted that strategies focusing on user behaviour to foster energy savings are lacking a sufficiently-evolved classification system. For example, the term 'feedback system' is often used to indicate anything from consumer-awareness displays (e.g., monitor screens showing current energy use) to informative meetings with users where opinions are given on various aspects of energy demands and system performance. Secondly, the studies available often focus on various types of building services and plug loads, whereas research specifically centred on (day)lighting energy use is rather sparse. Therefore, papers focusing on building services other than electric lighting were included when findings supported some conclusions on lighting energy use. Thirdly, lighting studies investigate mostly electric lighting, but as many papers as possible were included for which daylighting was considered. The following groups of strategies have been identified for this exploratory review: 1) information strategies and feedback; 2) social norms; 3 ) lighting control settings and occupantcentred adaptation; 4) design of the control interface; and, 5) rebound effects.

\subsection{Information strategies and feedback}

Under the banner of information strategies, we discuss notions and evidence provided to occupants to raise awareness on the impact of lighting use, e.g. on energy bills. For feedback systems, we more specifically describe any information strategy based on energy monitors or similar devices. A number of theoretical frameworks may be adopted when studying information strategies. The Theory of Planned Behaviour (TPB) fits well with this purpose (Ajzen, 1985). TPB assumes that behavioural choices of individuals are based on selfish evaluations of the effort needed to get to a desired result, and on the individual's perceived appreciation by the community. Final behaviours are based on a consequent cost-benefit evaluation.

Carrico and Riemer (2011) explored the benefit of information and feedback by dividing 24 employees into four groups: 1) a control group; 2) a group provided with peer education on energy-saving behaviours in offices (information); 3 ) a group provided with feedback (monthly email with energy use data); and, 4) a group provided with both peer education and feedback. They found that all information and feedback strategies achieved energy savings, reaching up to $8 \%$ (compared to the control baseline) for the group with both peer education and feedback.

A mixed information-feedback strategy was used by Orland et al. (2014), who assigned 41 employees for 6 months to a web-based game (information) in which they had to keep some chickens alive and healthy by saving energy for office appliances every day with respect to a 
baseline (feedback). They detected up to $23 \%$ energy savings, but little persistency of the energy-saving behaviour after the end of the feedback game. Gustafsson et al. (2009) included a remote team competition for a similar game for households. They detected relevant energy savings, with some participants going as far as lighting candles to save energy for lighting.

Information alone is also very important. Akashi and Neches (2005) showed that informing users of the importance of reducing lighting loads could let them accept an 80 lux lower target illuminance compared to uninformed users, yet without a decrease in performance. The benefits of feedback alone have also been proven, although potential savings are debated (Karlin et al., 2015), and interventions may lack in persistency of the behaviour (Murtagh et al., 2013).

Tetlow et al. (2014) tested a standard pictorial (bulb and text "Switch lights off") and a normative cue (person and text " $83 \%$ (of people, tacit) switch lights off)" prompt, both inviting people to turn off lights when leaving a meeting room. Each prompt consisted of a $120 \times 120 \mathrm{~mm}$ cardboard placed on a meeting room door. These prompts increased the frequency of switch-off after meetings, with the normative cue being significantly more effective than the standard pictorial. The authors also found that a manual switch-off occurred $58 \%$ of the times when a prompt was used, compared to just $3 \%$ in an equivalent meeting room with passive infrared (PIR) absence sensor. This may confirm that users tend to rely too much on technology (Pigg et al., 1996).

Lighting itself may also be turned into an immediate and effective feedback system. Maan et al. (2011) found that using a light source gradually shifting from green (low energy use) to red (high energy use) projected behind the desk is more effective than a numerical feedback indicating current power consumption in Watts. In their setting, the lighting feedback achieved $21 \%$ lower energy use compared to the numerical feedback. Lu et al. (2016) found that the effectiveness of lighting feedback increased with the consistency of the colour message.

Meerbeek et al. (2016) explored the use of feedback for shading devices. They used a custom interface on top of a virtual window where information on intensity of solar radiation was shown on a progress bar, while two arrows (up and down) suggested the need to lower or raise the shading device. The authors explored three levels of automation of the shading device: fully automated with no feedback and system acting (i.e., no manual override); automated system suggesting (feedback) and acting (manual override possible); and, manual with feedback. In addition, they tested two different forms of "expressions" of the feedback, indicating an increasing urgency to adjust the shading: one with an arrow slowly changing from green to red, the other with a red arrow blinking at progressively higher frequency. They found that users decreased the frequency of manual corrections of automatic adjustments when feedback occurred $(24.8 \%$ and $50.8 \%$, respectively), and that the blinking expression was slightly more effective than the slowly changing one. In addition, all systems providing feedback were highly appreciated by occupants, with users providing positive comments.

\subsection{Social norms}

So far, we reported on strategies evaluating the behaviour of the individual outside his/her social sphere, although too often it is neglected that energy behaviours heavily depend on social norms. This is well explained by the value-norm-belief theory (Stern, 2000), which links energy behaviour to aspects concerning one's own self, others, and the environment.

Literature on social norms and group dynamics is wide, and studies on lighting focus mostly on dynamics in open plan offices. In a field study involving 14 open-plan offices, Moore et al. (2002) showed that locally-controlled luminaires are switched more frequently, possibly because the switch would not affect other users. A more recent study (van de Werff et al., 2017) confirmed this finding, also postulating that lighting is adjusted only if it does not lead to conflicts in a shared environment. Although conflicts are usually avoided, Lashina et al. (2019) found that some users would tend to change the lighting setting anyway (dominant behaviour), while other users would just accept the change, even if they are not satisfied with the new lighting conditions (submissive behaviour). However, some users do not react to changes because they have high tolerances to lighting variations (Despenic et al., 2017). Staddon et al. (2015) reviewed available evidence on interventions to change behaviour and save energy in the workplace. They set out to identify what types of interventions to change behaviours are most successful at saving energy in an office-type workplace. They found that interventions creating social and physical opportunities for employees, i.e. enablement (such as giving greater control 
or better support to employees), environmental restructuring (such as real-time feedback and automated systems) and modelling (various forms of social influence) are the most successful. However, in addition to individual and collective actions of employees, energy savings also depend on the attitudes and engagement of management with respect to organisational change and investment in energy-efficient technology

\subsection{Lighting control settings and occupant-centred adapation}

Based on several standards and regulations from around the world, 500 lux is a common horizontal illuminance target for the task area in a traditional office setting as this is thought to balance user preference, visibility, and energy use. Some studies claimed that the preferred illuminance is a dynamic definition, as it seems to depend on the individual (Boyce et al., 2000), on the lighting source - whereby a lower illuminance is preferred when provided by daylight (Escuyer and Fontoynont, 2001) - and on the previous lighting conditions experienced.

With respect to the latter, a series of studies investigated the effects of the anchor point (i.e., the initial lighting setting) and of the stimulus range on user preference for manually controlled lighting. If manual dimming is provided, Logadottír et al. (2011) demonstrated that individuals tend to choose lower illuminance levels when the anchor point is lower and the stimulus range narrower. These findings were also confirmed by Uttley et al. (2013). Although Logadottír et al. (2011) warned of experimental pitfalls in preference studies, their conclusions may point towards design solutions leading to energy savings. For example, Logadottír (2015) carried out a follow-up study where a $50 \%$ difference in energy use was detected based on initial anchor points ( 0 lux and 500 lux). It has also been shown that the anchor point in lighting affects other visual responses, such as glare perception. Osterhaus and Bailey (1992) found that individuals first experienced glare at a higher luminance when they were adapted to a higher initial luminance, rather than a lower luminance, a finding confirmed by a more recent study (Kent et al., 2019a). Similarly, it has been shown that glare evaluation is also affected by stimulus range, whereby high ranges are associated with higher tolerated luminance (Kent et al., 2019b). In terms of previous lighting conditions, but in a perspective of integrated design, a study demonstrated that individuals were more likely to keep default lighting settings if these were provided by daylight (Heydarian et al., 2016). As an implication, providing abundant daylight as a default setting, e.g. shading devices open at the beginning of the day, would significantly lower the possibility that occupants turn on electric lighting during the day.

A further set of studies investigated the perception of dimming speed (up and down) in automatic systems. A study showed that more than half of individuals might not notice a $20 \%$ reduction of illuminance (Chraibi et al., 2018). In addition, the detection of changes increased when the speed of dimming went from 5 lux/s to 50 lux/s. When the fading-out is slower than 1 lux/s, an illuminance reduction above $20 \%$ might still not be detected (Akashi and Neches, 2005). While these studies are based on individual responses for personal lighting, Chraibi et al. (2018) tested dimming speed in open plan offices, whereby the variation of illuminance from a ceiling luminaire placed above a desk would also be perceived by other occupants. The authors dimmed up or down the illuminance on a desk between 543 lux to 345 lux at different speeds $(0 \mathrm{~s} / \approx 800 \mathrm{lux} / \mathrm{s}-2 \mathrm{~s} / 133 \mathrm{lux} / \mathrm{s}-5 \mathrm{~s} / 45 \mathrm{lux} / \mathrm{s})$. As a general conclusion, they found that dimming occurring in at least 2 seconds within the given stimulus range, i.e. $133 \mathrm{lux} / \mathrm{s}$, remained unnoticed or acceptable for more than $70 \%$ of the 17 study participants. In integrated design, daylight works as a mediating factor in the perception of light fading. A study by Newsham et al. (2008) surveyed 39 individuals who underwent 42 different trials in private daylit mock-up offices, while performing computer-based tasks under various daylight conditions. The electric lighting was set to full output at the start of the trial, and then dimmed down to the target of 400 lux. Successively, the electric lighting output was further reduced by $20 \%, 40 \%, 60 \%$, and $80 \%$ over periods of 10 seconds each. The study confirmed that a reduction of $20 \%$ illuminance - provided, in this case, by a mix of daylight and electric lighting - is unlikely to be noticed. However, with high daylight provision, this $20 \%$ actually corresponds to up to $60 \%$ of dimming down of electric lighting (Newsham et al., 2008).

Finally, the electric lighting should be switched off when not needed, e.g. when daylight can provide the necessary illumination or the occupant leaves the room. Unwanted switching off may generate aversion and could lead to sabotage of the lighting system. For daylight-linked systems, the previous knowledge on dimming speed suggests that a smooth and slow fade-out 
of electric lighting is unlikely to be noticed. For electric lighting, occupancy sensors' false switch-off events can be minimized either technically, by improving the sensor detection technology and its positioning, or non-technically, by understanding the frequency of detectable occupant movements and setting an appropriate switch-off time delay. For the latter, which is of interest here, the literature does not yet provide extensive information (de Bakker et al., 2017). However, a review by Guo et al. (2010) suggests that 7 minutes is the minimum time delay for traditional passive infrared (PIR)-based sensor with careful design and commissioning in a regularly-occupied space. In a study by Floyd et al. (1996), this led to $19 \%$ energy savings compared to the pre-retrofit energy use. Finally, a fade-out phase seems to make the transition from lights on to off almost imperceptible to occupants (de Bakker et al., 2017).

Nagy et al. (2015) designed and tested an adaptive lighting control strategy in offices based on the assumption that each occupant is unique but consistent in his/her action and that appropriate set-points for turning electric lighting on and off can be derived from statistical analysis. For this analysis, the researchers relied on data recorded by the building management system from occupancy sensors, manual occupant interaction with the lighting system via switches, illuminance levels in the room, and on/off status of the electric lights. A suitable algorithm was implemented in the controller. Through statistical analysis of recorded data in individual offices, suitable set-points for the time delay (for turning off electric lights), minimum (below which the system turns the electric lights on) and maximum (above which the system turns the electric lights off) illuminance thresholds were identified. Over a period of six weeks and associated system-learning, unique set-points for time delay and illuminance were achieved for each of the eight studied office spaces. Energy savings after six weeks were $37.9 \%$ compared to the standard setting control baseline.

\subsection{Design of the control interface}

A well-designed control interface can increase interactions by the occupant, which should lead to a better or more appropriate use of the control. If the control has been designed to save energy, then an increase in interaction would likely increase savings.

Interface design and placement of lighting and daylighting control devices have rarely been explored in the domain of integrated solutions. Few studies have investigated the case of electric lighting controls, and even fewer have included daylighting controls. Most research has been carried out in the field of human interaction, and particularly with respect to the definition of general design principles, but without a clear link to achievable energy savings. Two studies proposed a theoretical framework to study interactions between user and interface. The first (Dugar et al., 2011) explored the concepts of usability and end-user experience of the interface. The second (Maleetipwan-Mattsson et al., 2017) was based on the concepts of "affordance" (Gibson, 2014) of the interface, i.e. the support that the interface provides to the individual, plus other characteristics. According to the authors, the explored concepts aim at providing optimal use of the interface.

Dugar et al. (2011) evaluated the usability and end-user experience for three manual dimmer designs (push-button, rotary and slider dimmers, possibly combined with some indicator to show the level of dimming) and four virtual interfaces providing scene control. The authors observed that users interact with the interface in the way they find easiest, though not necessarily the most appropriate one. Also, the lighting control is more "tangible" when: 1) the interface has a reach representation of the functioning itself, e.g. by using indicators for the level of dimming; 2) when it provides feedback on the use; and, 3) when it provides a multi-sensory interactive experience, for example by merging tactile and graphical information. The same research group designed and tested a "tangible" interface consisting of touchscreen-based scene controller with graphical information and preview of the light scene change. They compared this solutions with a touchscreen interface with only text information, finding that the tangible interface significantly improved the learning speed and overall appreciation (Dugar et al., 2012).

Maleetipwan-Mattsson et al. (2017) carried out three field studies on the evaluation of the design characteristics, user perception of the interface, and observation of behaviours with different interfaces. The first two studies identified that a good switch interface should be: 1) simple and easy to use (affordances); 2) perceived as safe (e.g., no red warning lights); 3) able to trigger energy saving; 4) visible; 5) suitable for the context; and, 6) hygienic, this latter being particularly relevant for public buildings. In the third field experiment, they observed the use of 
light switches in a public toilet, finding that a classic, yet oversized, switch would increase the manual turn-off events, with obvious impact on energy use. In another study, MaleetipwanMattsson et al. (2016) found energy saving of 31 and $61 \%$ when using different interfaces in the dining and the dayroom, respectively. Traditional white push-on buttons seemed to promote interactions in dining rooms, and similar but coloured switches seemed to promote interactions in the dayroom. To the authors' knowledge, this study is the only one providing hard numbers on potential energy savings from interface design.

A study by YIlmaz et al. (2016) evaluated "people-friendliness" of different traditional and touchscreen interfaces for switches, dimmers and correlated colour temperature (CCT) tuners. Users appreciated most traditional interfaces and saw favourably any simple, immediately understandable, and responsive interface that could provide a clear feedback, e.g. the toggle being on the "on" or "off" position. Preference for "traditional", "common" or "standard" interface was found in various studies. These considerations led to the proposal of a standard for lighting control interfaces (Nordman et al., 2012; Nordman, 2017). A recent qualitative study based on semi-structured interviews with academic staff suggests that such standard is today more needed than ever (van Someren et al., 2018). The authors highlighted how interfaces, placement and complexity of the lighting controls discourage and bewilder users, with one interviewee explicitly longing for standardization.

The aforementioned study by Yılmaz et al. (2016) found that complex interfaces generated confusion, especially among users with no expert knowledge of lighting, for example some users could not grasp the concept of a "light scene", or the "K" (for Kelvin) unit of CCT for the colour tuner. The latter was frequently confused with energy units (kWh). Interface complexity is a matter to be taken seriously, especially with so-called "smart lighting", where interactions imply switching, dimming, and tuning. In such context, van de Werff et al. (2017) explored how the use of three innovative lighting control interfaces could affect the use of the lighting system in a shared office environment. The authors substantially confirmed the principles of "tangibility" expressed by Dugar et al. (2011), but they also found that mobile phone apps are less appreciated as lighting controls compared to dedicated controls. However, the number of interactions mainly varied between individuals rather than interface designs, but all interfaces received a gradually reducing number of interactions, suggesting a sort of behavioural "wow" factor that fades with time. To avoid this, one could deprive the user of the interface for then providing it again later; this would prompt a so-called "loss aversion" (Lashina et al., 2019). In a study of lighting in open plan offices, indeed, Lashina et al. (2019) found that individuals appreciate and use the interface more frequently after the forced loss.

In integrated daylighting and electric lighting design, a study observed users' interactions with motorized roller shades and dimmable electric lighting using traditional tangible controls and web-based interfaces in individual offices, as well as automated controls (Sadeghi et al., 2016). The study showed that users operate shading devices and electric lighting interdependently if given the opportunity to do so, i.e. by co-locating shading and electric lighting controls.

\subsection{Rebound effects}

User-driven strategies can increase savings from efficient technologies, but sometimes efficient technologies may also paradoxically promote energy use. In economics, such phenomenon is called a rebound effect (Khazzoom, 1980).

Tsao and Waide (2010) state that, over the last three centuries, expenditure for artificial lighting (including candles and gas lighting) steadily accounted for $0.72 \%$ of the gross domestic product. This implies that the per-capita use of artificial lighting grew constantly, resulting in a $100 \%$ rebound effect, and reached $130 \cdot 10^{15}$ lumen-hours in 2005. Borenstein (2014) proposed a simple model to estimate energy rebound effects, founded on a number of income-based constraints and assumptions. The model was applied to the hypothetical case of lighting in the U.S., obtaining a $43 \%$ increase (rebound-effect) when substituting incandescent sources with LED bulbs. Luckily, real data showed that such figures were a bit pessimistic. In the same year, Schleich et al. (2014) published a survey conducted in 6409 German households, finding that the total energy rebound effect due to the transition from incandescent to LED sources was only about $6 \%$, while light source efficacy increased from about $15 \mathrm{~lm} / \mathrm{W}$ with incandescent bulbs to at least $100 \mathrm{Im} / \mathrm{W}$ with LEDs. A large part of the rebound effect found by Schleich et al. (2014) was due to a higher lumen (Im) rating, implying that the LED sources delivered on average $24 \%$ 
more lumens then the bulb it replaced. On average, the more efficient LED sources were also kept on 8 minutes longer then the less efficient ones.

Porrit et al. (2013) hypothesized that required lumens per-capita may increase in the future due to an ageing population with lower visual acuity, and growing floor area per person, i.e. a wealthier population living in bigger houses. An unknown - and probably unknowable - risk is that cheaper and versatile light sources affect lighting design, resulting in much higher rebound effects. However, not every rebound effect is bad. Increased access to lighting has historically triggered essential societal changes, as recognized by the United Nations (2013). For example, spreading of access to electric lighting in developing countries should probably give greater weight to resultant welfare gains rather than energy issues (Saunders and Tsao, 2012). Conversely, electric lighting would also substitute more dangerous and polluting artificial light sources, making "lightification" a matter of equality, democracy, and, ultimately, justice.

\section{Discussion and conclusions}

The literature review has highlighted the following:

- Daylighting: This remains the preferred light source for the majority of users and better daylighting provision - in combination with appropriate supplementary electric lighting - can lead to substantial energy savings. Building occupants typically accept lower illuminance levels when the essential illumination is provided (or, at least, is perceived to be provided) by daylight rather than electric lighting.

- Energy savings: Potential savings have been reported from the retrieved studies. However, these savings are often derived from a single study and they are dependent on the specific context. In other words, the ecological validity of findings is usually low. Studies on strategies like information, feedback, and social norms did not report energy saving performance. This is an interesting conclusion in itself, since the papers rather suggest that the potential is high but deserves further exploration. Quantifying potential savings is fundamental to fostering the adoption of user-driven strategies on a large scale, since this would allow investors to make at least a rough estimation of returns. However, such quantification requires that studies are designed with an inter-disciplinary approach in mind. For example, during the review process, it was noticed that social science studies tend to provide comprehensive but only qualitative results, while engineering studies tend to measure energy effects of the intervention, but their experimental designs lack solid theoretical frameworks and results cannot be transferred easily to other contexts. A study design involving expertise from different disciplines would eventually overcome these limitations. Encouraging users to be more conscious of their lighting energy use behaviour can likely achieve sizeable energy savings. However, the savings potential is purely hypothetical at this point and greatly affected by many aspects that are highly situation-specific. It seems therefore necessary to conduct more purposeful studies on integrated lighting design solutions addressing lighting and lighting-related energy aspects from daylight, electric lighting, and shading systems before better and more specific recommendations can be made.

\section{- Design recommendations:}

- Manual or partially-automated shading devices provide higher satisfaction and encourage appropriate use, while fully-automated system are more likely to be overridden (Meerbeek et al., 2016). The use of manual and partially-automated shading devices benefits from feedback systems (Meerbeek et al., 2016), and users tend to act simultaneously on lighting and shading when the control interface is unique and conveniently located (Sadeghi et al., 2016).

- Energy savings can be fostered by dimming electric light, provided that the speed and range of variation is appropriately regulated (Newsham et al., 2008). Shading automation may be limited to opening shading devices at the end of the day to maximize daylight, since users usually maintain the default setting.

- Fully automated controls with occupancy sensor and on/off switching should be avoided as they increase energy use in most cases, even when compared to manual switching. In some settings, it might even be better to use manual lighting controls only. Energy 
code requirements might require revision to permit this. Lighting controls offering appropriate, gradual, and un-noticeable changes in illuminance levels are less likely to annoy occupants. Those with built-in system-learning capabilities, adapting to user preferences over time, seem to represent a promising path, but additional research is needed on how to best implement such systems in a variety of settings, especially in larger spaces with multiple occupants. Intuitive and tangible lighting controls constitute another topic deserving increased attention. Standards for lighting control devices can perhaps address this on the basis of accurate interdisciplinary scientific studies with different user groups.

- Social norms play an increasing role in affecting energy-use behaviours. These can likely be reinforced by feedback from lighting and shading control systems via clearly articulated and intuitive, graphically-supported, prompts. If some users, e.g. colleagues, are seen making an effort for energy conservation, other occupants might be persuaded to do the same.

- Rebound effects increasing the use of energy associated with lighting - despite higher efficacy $(\mathrm{Im} / \mathrm{W})$ of light sources - have also been observed. This appears to be related to the perception that more efficient light sources can be used more frequently and perhaps in more places than those with lower efficacy. However, these effects might also be due to increased lighting needs of an aging population and a higher area-per-person ratio in many building types, especially residences. More detailed studies addressing energy use (e.g. before and after lighting retrofits) in various sectors of the lighting market would be useful to identify areas where rebound effects pose particular threats to energy conservation targets.

This paper has explored some "user-driven strategies" to save energy in the field of integrated lighting design. The strategies listed above suggest that sizeable energy savings can be achieved by encouraging users to be more conscious of their behaviour with respect to energy use for lighting. However, the saving potential is purely hypothetical and greatly affected by a number of aspects that are situation-specific.

The literature survey found that several topics relevant to energy efficiency and user behaviour have not yet been sufficiently explored in lighting research, while more knowledge is available in other areas of building energy services. In particular, research on feedback systems and social norms in integrated lighting design is urgently required. Some topics, like rebound effects, represent risks rather than opportunities, but reinforce the need for a deeper understanding of energy-related behavioural patterns and decision-making processes of building owners, designers, lighting suppliers, installers and end-users. The literature also showed that strategies are more successful in integrated design, which calls for more communication between façade and lighting designers in future building processes. Finally, we argue that research on user-driven strategies is today more needed than ever, as the level of efficiency in lighting is getting so high that further gains from technological advances may become marginal.

\section{Acknowledgments}

The authors wish to express their gratitude to the funding agencies supporting their work in IEA SHC Task 61/EBC Annex 77, including this review: the Swedish Energy Agency, the Danish Energy Agency, the Foundation of Research Support of the Federal District (FAP-DF) and National Council of Scientific and Technological Development (CNPq) (Brazil), the Australian Renewable Energy Agency (ARENA) International Engagement Program, Norconsult AS (Norway).

\section{References}

AJZEN, I. 1985. From Intentions to Actions: A Theory of Planned Behavior, in: Kuhl, P. D. J. and Beckmann, D.J. (eds). Action Control: From Cognition to Behavior. Berlin: Springer, 11-39.

AKASHI, Y., NECHES, J. 2005. Potential recommendations for illuminance reductions by loadshedding. Lighting Res. Technol., 37 (2), 133-150. 
DE BAKKER, C., ARIES, M., KORT, H., ROSEMANN, A. 2017. Occupancy-based lighting control in open-plan office spaces: A state-of-the-art review. Build. Environ., 112, 308-321.

DE BOER, J. 2018. IEA SHC Task 61/EBC Annex 77 Workplan. Stuttgart: Fraunhofer IBP.

BORENSTEIN, S. 2014. A Microeconomic Framework for Evaluating Energy Efficiency Rebound and Some Implications. The Energy Journal, 36, 1.

BOYCE, P.R., EKLUND, N.H., SIMPSON, S.N. 2000. Individual Lighting Control: Task Performance, Mood, and Illuminance. J. Illum. Eng. Society, 29(1), 131-142.

CARRICO, A. R., RIEMER, M. 2011. Motivating energy conservation in the workplace. Journal of Environmental Psychology, 31(1), 1-13.

CHRAIBI, S., CREEMERS, P., ROSENKÖTTER, C., VAN LOENEN, E. J., ARIES, M. B. C., ROSEMANN, A. L .P. 2018. Dimming strategies for open office lighting: User experience and acceptance. Lighting Res. Technol., doi: 10.1177/1477153518772154.

DESPENIC, M., CHARAIBI, S., LASHINA, T., ROSEMANN, A. L. P. 2017. Lighting preference profiles of users in an open office environment. Build. Environ., 116, 89-107.

DUBOIS, M.-C., BISEGNA, F., GENTILE, N., KNOOP, M., MATUSIAK, B., OSTERHAUS, W., TETRI, E. 2015. Retrofitting the Electric Lighting and Daylighting Systems to Reduce Energy Use in Buildings: A Literature Review. Energy Research Journal, 6 (1), 25-41.

DUGAR, A.M., DONN, M.R., MARSHALL, S. 2012. Designing Tangible Lighting Control Interfaces. LEUKOS, 8(3), 215-228.

DUGAR, A. M., DONN, M. R., OSTERHAUS, W. 2011. Tangible lighting controls-Reporting end-users' interactions with lighting control interfaces. LEUKOS, 8(2), 123-136.

ESCUYER, S., FONTOYNONT, M. 2001. Lighting controls: a field study of office workers reactions. Lighting Res. Technol., 33(2), 77-94.

FLOYD, D. B., PARKER, D. S., SHERWIN, J. R. 1996. Measured Field Performance and Energy Savings of Occupancy Sensors: Three Case Studies, in: 1996 ACEEE Summer Study on Energy Efficiency in Buildings, Pacific Grove, CA: Florida Solar Energy Center, 97-105.

GIBSON, J.J. 2014. The ecological approach to visual perception. New York: Psychology Press.

GUO, X., TILLER, D.K., HENZE, G.P. 2010. The performance of occupancy-based lighting control systems: A review. Lighting Res. Technol., 42(4), 415-431.

GUSTAFSSON, A., KATZEFF, C.,BANG, M. 2009. Evaluation of a pervasive game for domestic energy engagement among teenagers. Computers in Entertainment, 7(4), 1.

HEYDARIAN, A., PANTAZIS, E., CARNEIRO, J. P., GERBER, D., BERCERIK-GERBER, B. 2016. Lights, building, action: Impact of default lighting settings on occupant behaviour. Journal of Environmental Psychology, 48, 212-223.

IEA-EBC. 2018. IEA EBC Annex 66 Definition and Simulation of Occupant Behavior in Buildings Annex 66 Final Report. Birmingham, UK: IEA.

IHM, P., NEMRI, A., KRARTI, M. 2009. Estimation of lighting energy savings from daylighting, Build. Environ., 44(3), 509-514.

JANDA, K.B. 2011. Buildings don't use energy: people do. Architect. Sci. Rev., 54(1), 15-22.

KARLIN, B., ZINGER, J.F. FORD, R. 2015. The effects of feedback on energy conservation: A meta-analysis. Psychological Bulletin, 141(6), 1205-1227.

KENT, M., FOTIOS, S., ALTOMONTE, S. 2019. Discomfort glare evaluation: The influence of anchor bias in luminance adjustments. Lighting Res. Technol., 51(1), 131-146.

KENT, M.G., FOTIOS, S., CHEUNG, T. 2019. Stimulus range bias leads to different settings when using luminance adjustment to evaluate discomfort glare. Build. Environ., 153, 281287.

KHAZZOOM, D.J. 1980. Economic Implications of Mandated Efficiency in Standards for Household Appliances. The Energy Journal, 1(4), 21-40. 
LASHINA, T., CHRAIBI, S., DESPENIC, M., SHRUBSOLE, P., ROSENMANN, A., VAN LOENEN, E. 2019. Sharing lighting control in an open office: Doing one's best to avoid conflict. Build. Environ., 148, 1-10.

LOGADÓTTIR, Á. 2015. A case study on occupant controlled lighting in offices, In: Proceedings of the 28th Session of the CIE, 28 June-4 July 2015, Manchester, UK: CIE.

LOGADÓTTIR, Á., CHRISTOFFERSEN, J., FOTIOS, S. 2011. Investigating the use of an adjustment task to set the preferred illuminance in a workplace environment. Lighting Res. Technol., 43(4), 403-422.

LU, S., HAM, J., MIDDEN, C. 2016. The influence of color association strength and consistency on ease of processing of ambient lighting feedback. Journal of Environmental Psychology, 47, 204-212.

MAAN, S., MERKUS, B., HAM, J. 2011. Making it not too obvious: the effect of ambient light feedback on space heating energy consumption. Energy Efficiency, 4(2), 175-183.

MALEETIPWAN-MATTSSON, P., LAIKE, T., JOHANSSON, M. 2016, Factors affecting optimal lighting use in shared hospital environments: A case-study. Build. Environ., 96, 260-269.

MALEETIPWAN-MATTSSON, P., LAIKE, T., JOHANSSON, M. 2017. The effects of user interface designs on lighting use. Journal of Engineering, Design \& Technology, 15(1), 5878.

MEERBEEK, B. W., DE BAKKER,C, DE KORT, Y.A.W. VAN LOENEN, E.J., BERGMANN, T. 2016. Automated blinds with light feedback to increase occupant satisfaction and energy saving. Build. Environ., 103, 70-85.

MOORE, T., CARTER, D. SLATER, A. 2002. A field study of occupant controlled lighting in offices. Lighting Res. Technol., 34(3), 191-202.

MURTAGH, N., NATI, M., HEADLY, W. R., GATERSLEBEN, B., GLUHAK, A., IMRAN, M. A., 2013. Individual energy use and feedback in an office setting: A field trial. Energy Policy, 62, 717-728.

NAGY, Z., YIK YONG, F., FREI, M., SCHLUETER, A. 2015. Occupant Centered Lighting Control for Comfort and Energy Efficient Building Operation. Energy and Buildings, 94, 100-108.

NEWSHAM, G. R., MANCINI, S., MARCHAND, R. G. 2008. Detection and acceptance of demand-responsive lighting in offices with and without daylight. LEUKOS, 4(3), 139-156.

NORDMAN, B. 2017. Lighting Control User Interface Standards [online]. Available at: nordman.lbl.gov/lightui [Accessed 29 April 2019].

NORDMAN, B., GRANDERSON, J., CUNNINGHAM, K. 2012. Standardization of user interfaces for lighting controls. Computer Standards \& Interfaces, 34(2), 273-279.

OIKONOMOU, V. BECCHIS, F., STEG, L., RUSSOLILLO, D. 2009. Energy saving and energy efficiency concepts for policy making. Energy Policy, 37(11), 4787-4796.

ORLAND, B., RAM, N., LANG, D., HOUSER, K., KLING, N., COCCIA, M. 2014. Saving energy in an office environment: A serious game intervention. Energy and Buildings, 74, 43-52.

OSTERHAUS, W. K. E., BAILEY, I. L. 1992. Large area glare sources and their effect on visual discomfort and visual performance at computer workstations, in: Conference Record of 1992 IEEE Industry Applications Society Annual Meeting, 4-9 Oct. 1992, Houston: IEEE, $1825-1829$.

PIGG, S., EILERS, M., REED, J. 1996. Behavioral aspects of lighting and occupancy sensors in privates offices: a case study of a university office building, In: Proceedings of the 1996 ACEEE Summer Study on Energy Efficiency in Buildings, Pacific Grove, ACEEE, 161-170.

PORRITT, J., TULEJ, S., MUCKLEJOHN, S. 2013. The rebound effect - An overview of the implications for lighting energy, In: Proceedings of the CIE Centernary Conference 2013, 15-16 April 2013, Paris, France, 203-210.

REINHART, C. F. 2004. Lightswitch-2002: a model for manual and automated control of electric lighting and blinds. Solar Energy, 77(1), 15-28. 
SADEGHI, S. A., KARAVA, P., KONSTANTZOS, I., TZEMPELIKOS, A. 2016. Occupant interactions with shading and lighting systems using different control interfaces: A pilot field study. Build. Environ., 97, 177-195.

SAUNDERS, H. D. TSAO, J. Y. 2012. Rebound effects for lighting, Energy Policy, 49, 477-478.

SCHLEICH, J., MILLS, B., DÜTSCHKE, E. 2014. A brighter future? Quantifying the rebound effect in energy efficient lighting. Energy Policy, 72, 35-42.

VAN SOMEREN, K., BEAMAN, C. P., SHAO, L. 2018. Users' experiences of lighting controls: A case-study. Lighting Res. Technol., 50(7), 1091-1106.

STADDON, S. CYCIL, C., GOULDEN, M., LEYGUE, C., SPENCE, A. 2016. Intervening to change behaviour and save energy in the workplace: A systematic review of available evidence. Energy Research \& Social Science, 17, 30-51.

STERN, P. C. 2000. Towards a Coherent Theory of Environmentally Significant Behavior. Journal of Social Issues, 56(3), 407-424.

TETLOW, R. M., BEAMAN, P., ELMUALIM, A. A., COULING, K. 2014. Simple prompts reduce inadvertent energy consumption from lighting in office buildings. Build. Environ., 81, 234242.

TSAO, J.Y., WAIDE, P. 2010. The World's Appetite for Light: Empirical Data and Trends Spanning Three Centuries and Six Continents. LEUKOS, 6(4), 259-281.

UNITED NATIONS 2013. Resolution adopted by the General Assembly on 20 December 2013 International Year of Light and Light based Technologies, 2015 [online]. Available at: http://www.un.org/en/ga/search/view_doc.asp?symbol=A/RES/68/221 [Accessed 29 April 2019]

UTTLEY, J., FOTIOS, S., CHEAL, C. 2013. Satisfaction and illuminances set with usercontrolled lighting. Archit. Sci. Rev., 56(4), 306-314.

VAN DE WERFF, T., NIEMANTSVERDRIET, K. VAN ESSEN, H. A., EGGEN, J. H. 2017. Evaluating Interface Characteristics for Shared Lighting Systems in the Office Environment, In: Proceedings of the 2017 Conference on Designing Interactive Systems - DIS '17, 1014 June 2017, New York, USA: ACM Press, 209-220.

YILMAZ, F., TICLEANU, C., HOWLETT, G. 2016. People-friendly lighting controls - User performance and feedback on different interfaces. Lighting Res. Technol., 48(4), 449-472. 